\title{
Growth of Zinc Oxide Nanocombs on Porous Silicon Layer by Thermal-Evaporation Method
}

\author{
Khaldun A. Salman \\ Solar Energy Researches Department, Al-Nahrain Nanorenewable Energy Researches Center, Al-Nahrain University, Baghdad, Iraq
}

Email address:

khaldunphysics@gmail.com

To cite this article:

Khaldun A. Salman. Growth of Zinc Oxide Nanocombs on Porous Silicon Layer by Thermal-Evaporation Method. Advances in Materials. Vol. 4, No. 2, 2015, pp. 30-35. doi: 10.11648/j.am.20150402.12

\begin{abstract}
Zinc oxide ( $\mathrm{ZnO}$ ) film was deposited on a porous silicon (PS) layer prepared by electrochemical etching through the thermal-evaporation method. $\mathrm{ZnO}$ nanocombs structure arrays were directly fabricated on the PS substrate through zinc powder evaporation, which uses a simple thermal-evaporation method without a catalyst. The $\mathrm{ZnO}$ nanocombs were highly oriented along the c-axis perpendicular to the PS layer. The average crystallite size of the PS and the $\mathrm{ZnO}$ nanocombs were 17.06 and $17.94 \mathrm{~nm}$, respectively. The photoluminescence emission spectra of the $\mathrm{ZnO}$ nanocombs grown on the PS layer showed three emission peaks. The two peaks located at 387.5 and $605 \mathrm{~nm}$ were caused by the $\mathrm{ZnO}$ nanocombs, whereas the third peak located at $637.5 \mathrm{~nm}$ was caused by the PS layer. The $\mathrm{ZnO}$ nanocombs grown on the PS layer exhibited exceptional light trapping at wavelengths ranging from 400 to $1000 \mathrm{~nm}$, which was expected to increase the efficiency of nano-electronic and nano-optical devices such as (solar cells).
\end{abstract}

Keywords: Zinc Oxide Film, Nanocombs, Porous Silicon Layer, Electrochemical Etching

\section{Introduction}

The unique optical and electronic properties of semiconductor nanostructures are significant to new technologies. These nanostructures are the key element in the development of nanoscale and nanosize applications. Among the possible semiconductors brought to the nanosize level, zinc oxide $(\mathrm{ZnO})$ is attractive because of its wide direct band gap $(3.37 \mathrm{eV})$, high exciton binding energy $(60 \mathrm{meV})$ at room temperature (RT), and wurtzite crystal structure [1]. ZnOattracts attention because of its multiple applications in laser diodes [2], transparent conductive contacts [3], and solar cells [4]. More recently, $\mathrm{ZnO}$ has been used for antireflection coating because of its good transparency and appropriate refractive index [5].A porous silicon (PS) layer was formed on a crystalline silicon (c-Si) wafer using electrochemical etching. The PS layer exhibited photoluminescent (PL) properties similar to those of semiconductors with a direct energy band gap[6]. PS layers are attractive materials for optoelectronic devices because they possess band gap broadening, wide optical transmission ranging from 700 to $1000 \mathrm{~nm}$, wide absorption spectrum, and surface roughness [7]. The combination of $\mathrm{ZnO}$ films and cSi samples are important, but the deposition of high-quality
$\mathrm{ZnO}$ films on c-Si samples introduces a stress between the materials because of the large mismatch in lattice constants and thermal expansion coefficients [8]. Despite these problems, $\mathrm{ZnO}$ nanocombs have been successfully deposited on silicon substrates [9].

The PS layer is a convenient material for accommodating the deposition of $\mathrm{ZnO}$ film, because it has a large internal surface area, high resistance, and strong absorbability [10]. The combination of $\mathrm{ZnO}$ films and PS layer is equally important because the deposition of high-quality $\mathrm{ZnO}$ films on a PS layer introduces a large matching of lattice constants and thermal expansion coefficients [11], which can lead to a newtype of functional material.

Different methods such as chemical vapor deposition [12, 13], sol-gel process [14], direct current sputtering[15], radio frequency sputtering [16], and thermal-evaporation have been proposed to deposit $\mathrm{ZnO}$ films on a PS layer [17]. Despite various methods of preparing $\mathrm{ZnO}$ layers with a nanostructure, there is still the need to develop a low-cost, reproducible method for creating these layers. In the current work, the $\mathrm{ZnO}$ nanocombs was fabricated at $800{ }^{\circ} \mathrm{C}$ through thermal evaporation of $\mathrm{Zn}$ powder, and the PS layer was prepared by electrochemical etching process. The morphological, structural, and optical properties of the produced $\mathrm{ZnO}$ nanocombs were investigated. 


\section{Experimental}

Electrochemical etching process was used to fabricate the PS layer on an n-type c-Si (100) wafer with resistivity of 1$20 \Omega \mathrm{cm}$ and a thickness of 356-406 $\mu \mathrm{m}$. The electrochemical etching cell had a circular aperture at the bottom that was sealed with the c-Si sample. Fig. 1 shows the two-electrode cell system made of Teflon and connected to the c-Si sample as the anode and platinum $(\mathrm{Pt})$ as the cathode.

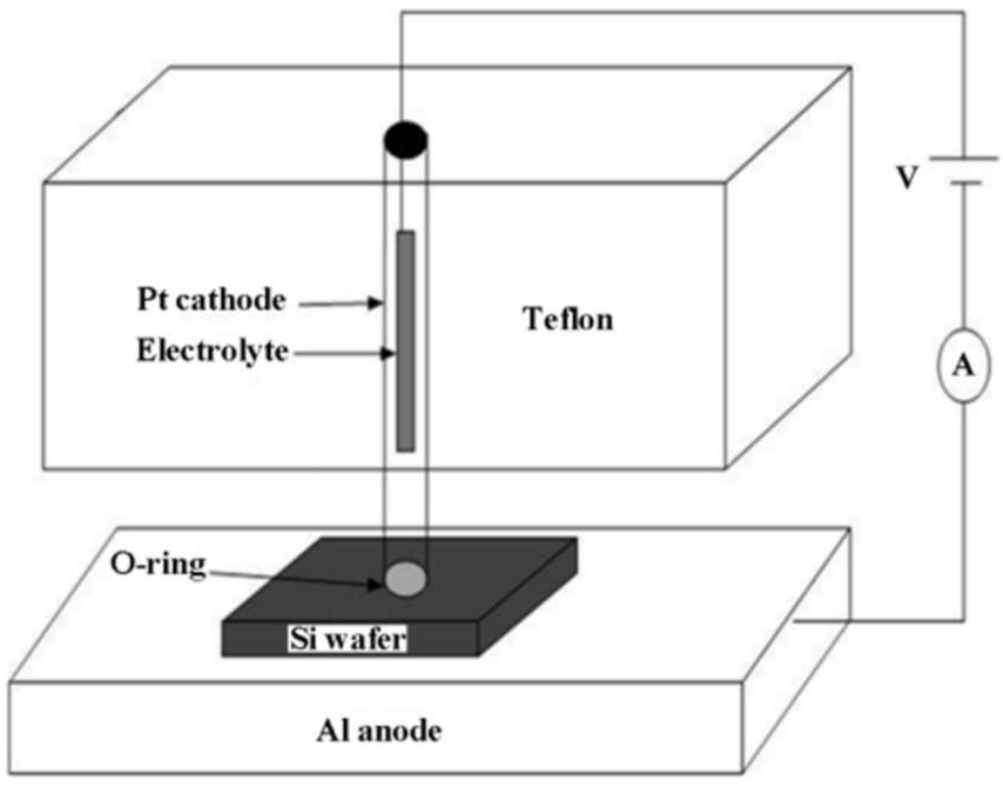

Fig. 1. The electrochemical etching cell set up.

The c-Si wafer was cleaned to remove the oxide layer using the Radio Corporation of America method. It was then placed in an electrolyte solution of $\mathrm{HF}(48 \%)-\mathrm{C}_{2} \mathrm{H}_{5} \mathrm{OH}(98 \%)$ ( $1: 4$ by volume) to enable conduction of electrons inside the solution. A current density of $60 \mathrm{~mA} / \mathrm{cm}^{2}$ and an etching time of 20 minutes were used to prepare the PS layer.

The synthesis was carried out at RT. The sample was rinsed in ethanol and air-dried after the etching process. The fabrication of the $\mathrm{ZnO}$ nanocombs was based on the thermalevaporation process of pure metallic $\mathrm{Zn}$ powder (99.9\%) without any catalyst [18]. The synthesis was carried out in a quartz tube. The PS layer was used as substrate and placed at an alumina boat toward the $\mathrm{Zn}$ powder. The alumina boat was then pushed to the center of a quartz tube furnace. The furnace was heated to $800{ }^{\circ} \mathrm{C}$ under a continuous flow of pure argon and oxygen gases. A constant flow rate of $300 \mathrm{sccm}$ was maintained for $1 \mathrm{~h}$. After the evaporation was completed, the alumina boat was slowly drawn out from the furnace and cooled down to RT.

Annealing of the $\mathrm{ZnO}$ nanocombs was done at $500{ }^{\circ} \mathrm{C}$ for 30 minutes under flowing $\left(4 \mathrm{~L} \mathrm{~min}^{-1}\right)$ nitrogen gas. Scanning electron microscopy (SEM) and energy dispersive x-ray (EDX) analysis (JSM-6460 LV, Japan) were used to determine the surface morphology and composition of the PS and $\mathrm{ZnO}$ nanocombs. To determine the $\mathrm{ZnO}$ crystallite structure, x-ray diffraction (XRD) measurements were carried out using a high-resolution x-ray diffractometer system (PANalyticalX'pert PRO MRD PW3040, Almelo, The Netherlands) with $\mathrm{Cu}_{-}$Karadiation at $0.15406 \mathrm{~nm}$. PL studies were carried out using a spectroscopy system (JobinYvon HR 800 UV, Edison, NJ, USA). The optical reflectance of the c-Si sample, PS layer, and $\mathrm{ZnO}$ nanocombs were obtained using an optical reflectometer (Filmetrics, F20, USA).

\section{Results and Discussions}

Fig. 2(a) shows the pores were randomly distributed on the surface of the PS layer, and that some pores were star-like and elongated. The average pore diameter was $5.7 \mathrm{~nm}$, which was calculated by Eq. 1 [19]:

$$
E(e V)=E_{g}+\frac{h^{2}}{8 d^{2}}\left[\frac{1}{m_{e}^{*}}+\frac{1}{m_{h}^{*}}\right]
$$

where $\mathrm{E}(\mathrm{eV})$ is the energy band gap of PS, $\mathrm{E}_{\mathrm{g}}$ is the energy band gap of bulk c-Si, $\mathrm{h}$ is Planck's constant $=4.13 \times$ $10^{-15} \mathrm{eV} \cdot \mathrm{s}, \mathrm{d}$ is the pore diameter, and $m_{e}^{*}$ and $m_{h}^{*}$ are the electron and hole effective mass, respectively (at $300 \mathrm{~K}, m_{e}^{*}=$ $=0.19 \mathrm{~m}_{\mathrm{o}}, m_{h}^{*}=0.16 \mathrm{~m}_{\mathrm{o}}$, and $\mathrm{m}_{\mathrm{o}}=9.109 \times 10^{-31} \mathrm{~kg}$ ). Moreover the surface of the PS layer was etched completely and consisted of tiny pores. These pores formed over the soft walls and increased the porosity of the PS layer to $75 \%$. Porosity was determined using Eq. 2 [20]:

$$
\mathrm{P}(\%)=\frac{\mathrm{m}_{1}-\mathrm{m}_{2}}{\mathrm{~m}_{1}-\mathrm{m}_{3}}
$$

where $\mathrm{P}(\%)$ is the porosity, $\mathrm{m}_{1}$ is the sample weight before anodization, $\mathrm{m}_{2}$ is the sample weight after anodization, and $\mathrm{m}_{3}$ is the sample weight after removing the PS layer with a $3 \%$ $\mathrm{KOH}$ solution in $50 \mathrm{~s}$ [21].

Fig. 2(b) shows the SEM image of the $\mathrm{ZnO}$ nanocombs grown on the PS layer. The $\mathrm{ZnOnanocomb}$ structures were randomly distributed above the PS layer. The $\mathrm{ZnO}$ 
nanocombsand the PS layer were composed of nanocrystals.
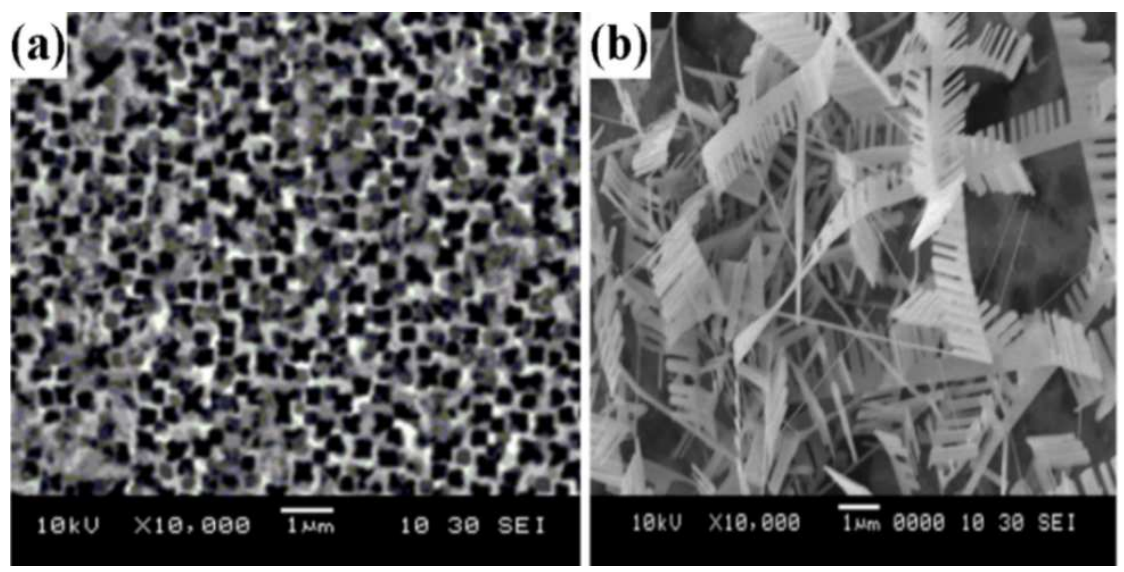

Fig. 2. SEM images of (a) PS layers, (b) ZnO nanocombs/PS layer.

Fig. 3 shows there is no clear boundary at the interface of the $\mathrm{ZnO}$ nanocombs. The $\mathrm{ZnO}$ nanocombsalong the walls partially filled or covered the pores of the PS layer during the thermal-evaporation process. In addition, the $\mathrm{ZnO}$ nanocombs were tightly connected to the PS layer.

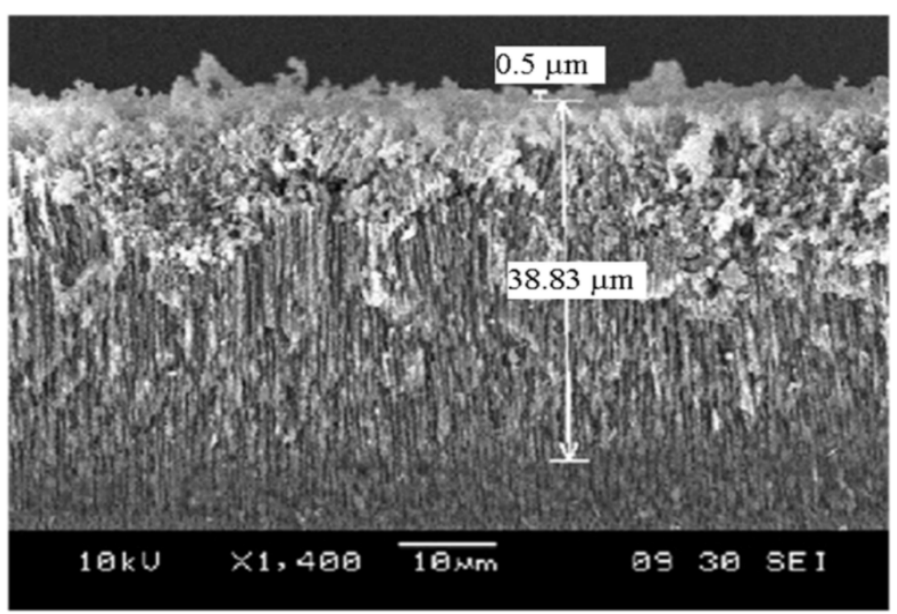

Fig. 3. SEM cross-section of the ZnO nanocombs/PS layer.

The irregular distribution of the $\mathrm{ZnO}$ nanocombs could enhance the photo conversion because of a widened PL peak. The SEM cross-section reveals the thickness of the PS layer was $38.83 \mu \mathrm{m}$, whereas the thickness of $\mathrm{ZnO}$ nanocombs was $500 \mathrm{~nm}$.

Fig. 4 shows the EDX spectrum and atomic composition of the $\mathrm{ZnO}$ nanocombs grown on the PS layer. It also describes the atomic composition of the elements in the layers. The concentrations of these elements are indicated by the peaks, with the elements corresponding to the peaks comprising the layer.

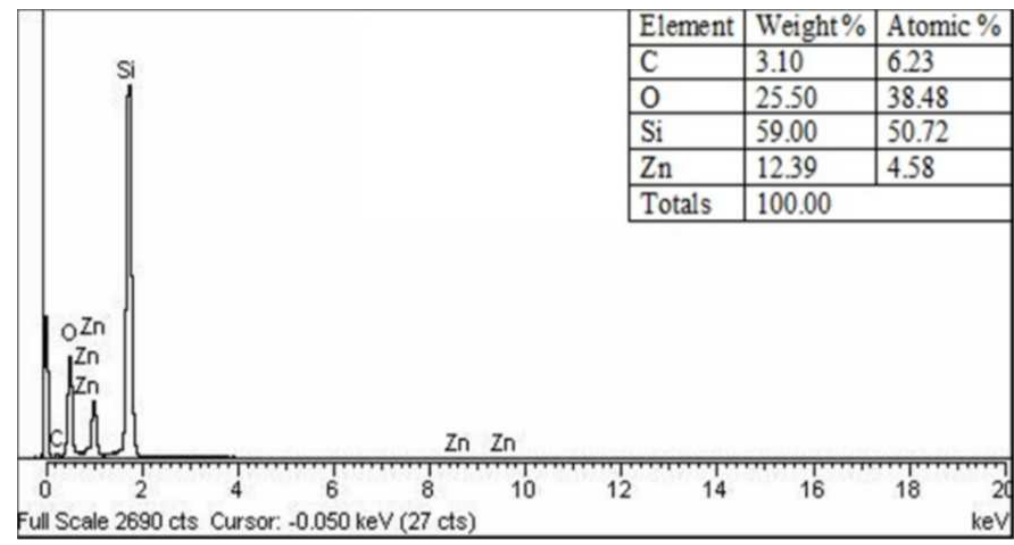

Fig. 4. EDX spectra of $\mathrm{ZnO}$ nanocombs/PS layer. 
Fig. 5 shows that the $\mathrm{ZnO}$ nanocombs grown on the PS layer exhibited a dominant diffraction peak at $2 \theta=69.09^{\circ}$, which corresponds to the PS layer [8]. The diffraction peak at $34.23^{\circ}$ corresponds to the (002) plane of the ZnOnanocomb, which indicates that the $\mathrm{ZnO}$ nanocombs were highly oriented along the c-axis vertical to the PS layer [11, 22]. The diffraction peak at $44.35^{\circ}$ is related to silicon carbide from the XRD sample holder [23].

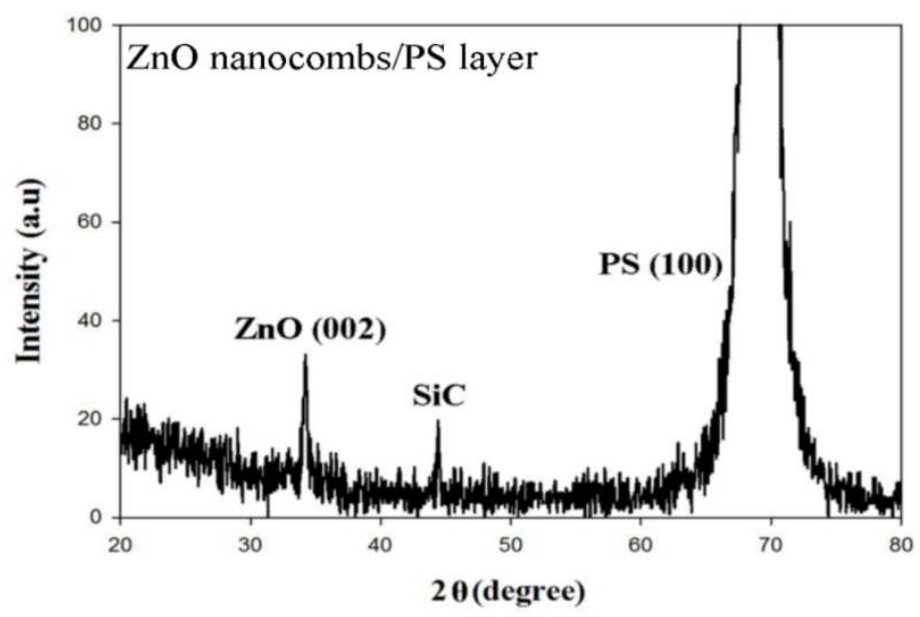

Fig. 5. XRD spectra of the ZnO nanocombs/PS layer

The average crystallite size was calculated using the Scherrer formula below [24]:

$$
\mathrm{D}=\frac{0.9 \lambda}{\mathrm{B} \cos \theta}
$$

where $\mathrm{D}$ is the average grain size, $\lambda$ is the $\mathrm{X}$-ray radiation wavelength $(0.15406 \mathrm{~nm}), B$ is the full width at half maximum value, and $\theta$ is the diffraction Bragg angle. The values of the average crystallite size obtained from XRD were $17.06 \mathrm{~nm}$ for the PS layer and $17.94 \mathrm{~nm}$ for the $\mathrm{ZnO}$ nanocombs. The decrease in average crystallite size indicated an increase in the porosity of the PS layer [25]. In addition, the strain $\left(\varepsilon_{\mathrm{zz}}\right)$ of the $\mathrm{ZnO}$ nanocombs grown on the PS layer along the c-axis can be calculated using Eq. 4 [26]:

$$
\varepsilon_{\mathrm{zz}}(\%)=\frac{\mathrm{c}-\mathrm{c}_{0}}{\mathrm{c}_{0}}
$$

where cis the lattice constant of the strained $\mathrm{ZnO}$ nanocombs calculated from XRD data, and $\mathrm{c}_{\mathrm{o}}$ is the unstrained lattice constant for $\mathrm{ZnO}$. The obtained value of strain is $0.36 \%$. A positive value is associated with tensile strain [27]. The low value of the tensile strain revealed that the $\mathrm{ZnO}$ nanocombs preferred to grow along the c-axis, and exhibited a highquality crystal resulting from a small lattice mismatch between the $\mathrm{ZnO}$ nanocombs and the PS layer (9.9\%). This is in contrast with the lattice mismatch between the $\mathrm{ZnO}$ film and the c-Si sample, which was at 39\%-40.2\% [28, 29].

Fig. 6 shows the PL spectra of the PS layer and the $\mathrm{ZnO}$ nanocombs grown on the PS layer measured at RT by $\mathrm{He}-\mathrm{Cd}$ excitation laser source at $325 \mathrm{~nm}$. The inset in Fig. 6 shows the PL spectrum of the PS layer exhibiting a very intense PL emission peak at $683.5 \mathrm{~nm}$, an indication of the good quality of the PS layer [30]. The left PL peak at $387.5 \mathrm{~nm}$ was caused by the near band edge emission in the wide band gap of the $\mathrm{ZnO}$ nanocombs, resulting from the direct recombination of photogenerated charge carriers $[31,32]$.

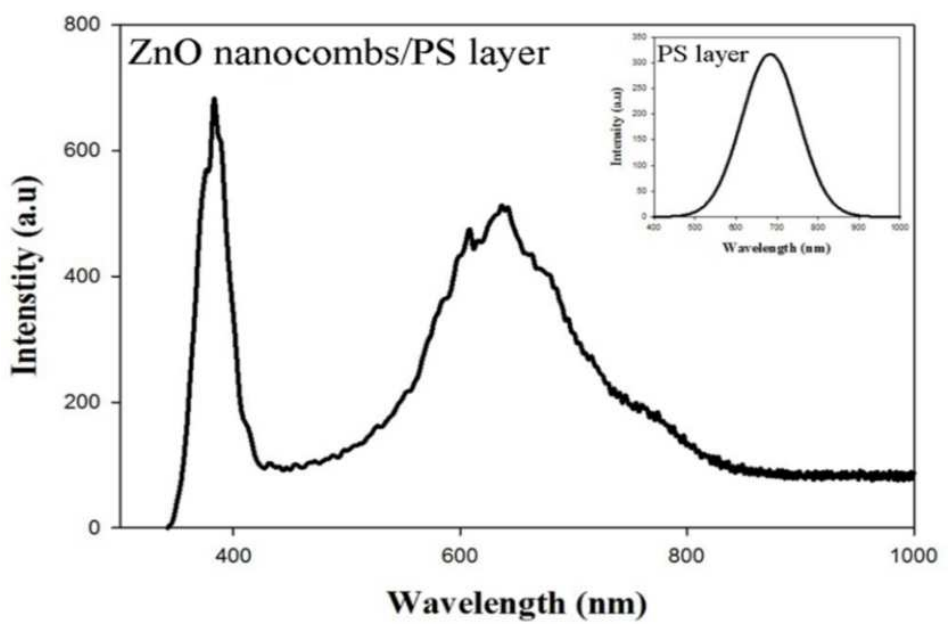

Fig. 6. PL spectra of the $\mathrm{ZnO}$ nanocombs/PS layer. 
The right, high-intensity PL peak at $637.5 \mathrm{~nm}$ is attributed to the PS layer $[33,34]$. The blue shift in the PL peak of the PS layer is attributed to the quantum confinement effect of electrons in nanosized particles in the PS layer [30, 35]. In addition, the observed emission at $637.5 \mathrm{~nm}$ is related to the surface oxidation by ZnOnanocomb deposition [36]. The red emission peak for the PS layer containing a shoulder peak at $605 \mathrm{~nm}$ in the visible region is related to the high number of intrinsic structural defects resulting from $\mathrm{Zn}$ vacancies [37].
As a result of the high porosity of the PS layer, the blue shift in the PL peak is possible, and the high intensity of the strong red emission occurs from the PS layer [32, 33, 38]. In other words, in low-dimensional structures, the probability of the recombination of electrons and holes will be higher, which will lead to increased optical confinement energy [39].

Fig. 7 shows the reflection spectra of the $\mathrm{ZnO}$ nanocombs grown on the PS layer compared to the c-Si sample and the PS layer.

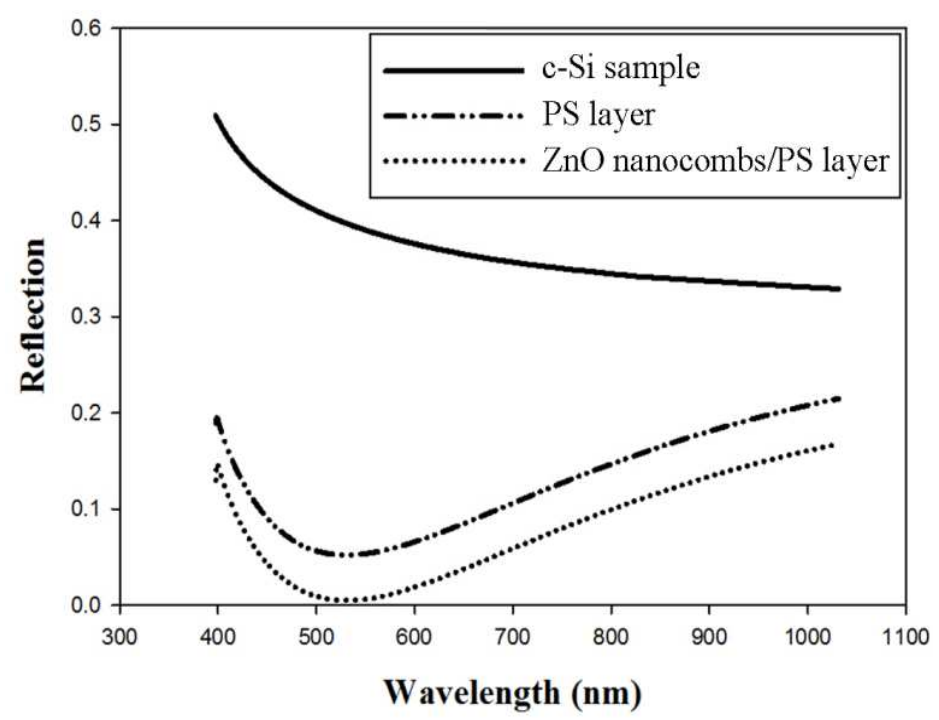

Fig. 7. Reflection spectra of the ZnO nanocombs/PS layer compared with the PS layer and as-grown Si sample.

The PS layer consisted of nano-silicon crystals and nanopores. Therefore, the refractive index decreased and was controlled by the pores with respect to the high porosity, which consequently led to a decrease in reflection [40]. The PS reduced light reflection at wavelengths ranging from 400 to $1000 \mathrm{~nm}$ compared to the reflectivity of the c-Si sample. However, the lowest effective reflectance was obtained from the $\mathrm{ZnO}$ nanocombs grown on the PS layer, which clearly reduced light reflection and increased light trapping at wavelengths ranging from 400 to $1000 \mathrm{~nm}$ compared to the reflectivity of the c-Si sample and PS layer. The maximum reduction in light reflection ranged from 450 to $650 \mathrm{~nm}$, and is attributed to the scattering and transmission of incident light caused by the $\mathrm{ZnO}$ nanocombs on the PS layer. A slight increase in reflection occurred from 650 to $1000 \mathrm{~nm}$, which may be caused by the random distribution of the $\mathrm{ZnO}$ nanocombs and the pores on the PS surface.

The synthesis of $\mathrm{ZnO}$ nanocombs on the PS layer could enhance the photo-conversion process with high transparency and increase light absorption in the near-UV/VIS region of the solar spectrum. As a result, the efficiency of nanoelectronic and nano-optical devices is expected to increase.

\section{Conclusions}

$\mathrm{ZnO}$ film was successfully synthesized on a PS layer using thermal-evaporation method. The PS layer was prepared with a current density of $60 \mathrm{~mA} / \mathrm{cm}^{2}$ and an etching time of 20 minutes using electrochemical etching method, resulting in $75 \%$ porosity. $\mathrm{ZnO}$ nanocombs were highly oriented along the c-axis perpendicular to the PS layer. The value of the tensile strain $(0.36 \%)$ revealed that $\mathrm{ZnO}$ nanocombs preferred to grow along the c-axis, and exhibited high-quality crystal resulting from a small lattice mismatch between the $\mathrm{ZnO}$ nanocombs and the PS layer (9.9\%).

The PL emission spectra of the $\mathrm{ZnO}$ nanocombs grown on the PS layer exhibited three emission peaks. The two peaks located at 387.5 and $605 \mathrm{~nm}$ were caused by the $\mathrm{ZnO}$ nanocombs, whereas the third peak at $637.5 \mathrm{~nm}$ was caused by the nanocrystalline PS layer. The $\mathrm{ZnO}$ nanocombs grown on the PS layerexhibited the lowest effective reflectance, which indicates excellent light trappingat wavelengths ranging from 400 to $1000 \mathrm{~nm}$.

The $\mathrm{ZnO}$ grown on the PS layer could enhance and increase the light conversion efficiency of nano-electronic and nano-optical devices as a result of the transparency and trapping of the incident radiation caused by the passivation and heterogeneous properties of the layers.

\section{References}

[1] R.C. Pawar, J.S. Shaikh, A.A. Babar, P.M. Dhere, P.S. Patil, Sol. Energy 85 (2011) 1119. 
[2] Z.Z. Ye, J.G. Lu, Y.Z. Zhang, Y.J. Zeng, L.L. Chen, F. Zhuge, G.D. Yuan, H.P. He, L.P. Zhu, J.Y. Huang, B.H. Zhao, Appl. Phys. Lett. 91 (2007) 113503.

[3] E.M. Wong, P.C. Searson, Appl. Phys. Lett. 74 (1999) 2939.

[4] L. Bahadur, M. Hamdani, J.F. Koenig, P. Chartier, Sol. Energ. Mater. 14 (1986) 107.

[5] Y.-J. Lee, D.S. Ruby, D.W. Peters, B.B. McKenzie, J.W.P. Hsu, Nano Lett. 8 (2008) 1501.

[6] L.T. Canham, Appl. Phys. Lett. 57 (1990) 1046.

[7] N. Koshida, H. Koyama, Mater. Res. Soc. Symp. 256 (1992) 219.

[8] H.-C. Hsu, C.-S. Cheng, C.-C. Chang, S. Yang, C.-S. Chang, W.-F. Hsieh, Nanotechnology 16 (2005) 297.

[9] C. Shaoqiang, Z. Jian, F. Xiao, W. Xiaohua, L. laiqiang, S. Yanling, X. Qingsong, W. Chang, Z. Jianzhong, Z. Ziqiang, Appl. Surf. Sci. 241 (2005) 384.

[10] O. Bisi, S. Ossicini, L. Pavesi, Surf. Sci. Rep. 38 (2000) 1.

[11] J.Y. Chen, K.W. Sun, Energy Mater. Sol. Cells 94 (2010) 930.

[12] K. Haga, P.S. Wijesena, H. Watanabe, Appl. Surf. Sci. 169170 (2001) 504.

[13] C.H. Zang, Y.C. Liu, D.X. Zhao, J.Y. Zhang, D.Z. Shen, J. Nanosci. Nanotechnol. 10 (2010) 2370.

[14] S. Fujihara, C. Sasaki, T. Kimura, Appl. Surf. Sci. 180 (2001) 341.

[15] G.L. Harding, B. Window, E.C. Horrigan, Sol. Energ. Mater. 22 (1991) 69.

[16] H. Cai, H. Shen, Y. Yin, L. Lu, J. Shen, Z. Tang, Chem. Solids 70 (2009) 967.

[17] H.I. Abdulgafour, F.K.Yam, Z. Hassan, K. Al-Heuseen, M.J. JawadJ. Alloys Compd. 509 (2011) 5627.

[18] C.S. Lao, P.X. Gao, R.S. Yang, Y. Zhang, Y. Dai, Z.L. Wang, Chem. Phys. Lett. 417 (2005) 359.

[19] P.L. Ossicini S. L., Priolo F., Light emitting silicon for microphotonics, Springer-Verlag, Berlin Heidelberg, 2003.

[20] J. Nijs, S. Sivoththaman, J. Szlufcik, K. De Clercq, F. Duerinckx, E. Van Kerschaever, R. Einhaus, J. Poortmans, T. Vermeulen, R. Mertens, Sol. Energy Mater. Sol. Cells 48 (1997) 199.

[21] S. Faÿ, A. Shah, in: K. Ellmer, A. Klein, B. Rech (Eds.), Transparent Conductive Zinc Oxide, vol. 104, Springer Berlin Heidelberg, 2008, p. 235.
[22] M. Gabás, P. Díaz-Carrasco, F. Agulló-Rueda, P. Herrero, A.R. Landa-Cánovas, J.R. Ramos-Barrado, Sol. Energy Mater. Sol. Cells 95 (2011) 2327.

[23] J.J. Hassan, Z. Hassan, H. Abu-Hassan, J. Alloys Compd. 509 (2011) 6711.

[24] B.D. Cullity, Elements of X-ray Diffraction, Addison-Wesley, London, 1959.

[25] J.J. Yon, K. Barla, R. Herino, G. Bomchil, J. Appl. Phys. 62 (1987) 1042.

[26] C.-Y. Tsay, K.-S. Fan, S.-H. Chen, C.-H. Tsai, J. Alloys Compd. 495 (2010) 126.

[27] R. Ghosh, D. Basak, J. Appl. Phys. 96 (2004) 2689.

[28] D.-T. Phan, G.-S. Chung, Appl. Surf. Sci. 257 (2011) 3285.

[29] N. Gopalakrishnan, B.C. Shin, H.S. Lim, G.Y. Kim, Y.S. Yu, Phys. B (Amsterdam, Neth.) 376-377 (2006) 756.

[30] C.H. Chen, Y.F. Chen, Appl. Phys. Lett. 75 (1999) 2560.

[31] C.-F. Yu, C.-W. Sung, S.-H. Chen, S.-J. Sun, Appl. Surf. Sci. 256 (2009) 792.

[32] A. Umar, B. Karunagaran, E.-K. Suh, Y.B. Hahn, Nanotechnology 17 (2006) 4072.

[33] Y.L. Liu, Y.C. Liu, H. Yang, W.B. Wang, J.G. Ma, J.Y. Zhang, Y.M. Lu, D.Z. Shen, X.W. Fan, J. Phys. D: Appl. Phys. 36 (2003) 2705.

[34] D. Verma, F. Khan, S.N. Singh, P.K. Singh, Sol. Energy Mater. Sol. Cells 95 (2011) 30.

[35] R.E. Hummel, M.H. Ludwig, S.S. Chang, Solid State Commun. 93 (1995) 237.

[36] E. Kayahan, J. Lumin. 130 (2010) 1295.

[37] O.D. Jayakumar, V. Sudarsan, C. Sudakar, R. Naik, R.K. Vatsa, A.K. Tyagi, Scr. Mater. 62 (2010) 662.

[38] R. Prabakaran, M. Peres, T. Monteiro, E. Fortunato, R. Martins, I. Ferreira, J. Non-Cryst. Solids 354 (2008) 2181.

[39] X.L. Wu, S.J. Xiong, D.L. Fan, Y. Gu, X.M. Bao, Phys. Rev. B $62(2000) 7759$.

[40] D.E. Aspnes, J.B. Theeten, F. Hottier, Phys. Rev. B 20 (1979) 3292. 